\title{
OCORRÊNCIA DO HERBICIDA TEBUTHIURON NA ÁGUA SUBTERRÂNEA DA MICROBACIA DO CÓRREGO ESPRAIADO, RIBEIRÃO PRETO - SP
}

\author{
MARCO ANTONIO FERREIRA GOMES * \\ CLÁUDIO A. SPADOTTO ** \\ VERA LÚCIA LANCHOTTE ***
}

\begin{abstract}
Pretendeu-se mostrar que o herbicida Tebuthiuron, selecionado entre outros usados na cultura de cana-de-açúcar, oferece risco de contaminação para a água subterrânea em função de suas características físico-químicas, principalmente, quando aplicado em áreas de recarga direta de aqüíferos consideradas de alta vulnerabilidade natural. Assim, efetuou-se monitoramento do referido herbicida no período compreendido entre 1995 e 1999, coletando amostras de água de poço semi-artesiano, com 53 metros de profundidade, localizado na microbacia do Córrego Espraiado, município de Ribeirão Preto/SP, Brasil, no qual tem sido freqüente o uso do produto em questão. Para efeito de testemunha da amostra de água foi considerado um poço semi-artesiano de profundidade semelhante, localizado cerca de três quilômetros de distância do poço objeto de monitoramento. Os resultados obtidos mostraram que o Tebuthiuron está presente em todas as amostras analisadas, embora em concentrações abaixo do nível crítico para padrão de potabilidade, conforme os limites mais restritivos estabelecidos pela Organização Mundial de Saúde (para os pesticidas em uso é de $0,1 \mu \mathrm{g} / \mathrm{L}$ por pesticida e de $0,5 \mu \mathrm{g} / \mathrm{L}$ para pesticidas totais). Mesmo com os baixos valores de concentração encontrados fica evidente que o Tebuthiuron está atingindo a água subterrânea podendo aumentar sua concentração pela existência de condições ambientais favoráveis à preservação da molécula em profundidade (tais como baixa temperatura, baixa atividade biológica e ausência de luz). Caso o nível crítico seja atingido, o risco de contaminação poderia ser minimizado por meio da substituição do Tebuthiuron por outro herbicida com menor mobilidade no perfil do solo.
\end{abstract}

PALAVRAS-CHAVE: TEBUTHIURON; ÁGUA SUBTERRÂNEA; AQÜÍFEROS.

* Geólogo; Doutor em Solos, Pesquisador da Embrapa Meio Ambiente, Jaguariúna, SP. (e-mail: gomes@cnpma.embrapa.br).

** Engenheiro Agrônomo, PhD em Ciência de Solo-Água, Pesquisador da Embrapa Meio Ambiente, Jaguariúna, SP.

*** Farmacêutica, Profá . da Escola de Ciências Farmacêuticas, Universidade de São Paulo (USP), Ribeirão Preto, SP. 


\section{INTRODUÇÃO}

A demanda pelo consumo de água subterrânea tem aumentado de forma expressiva em todo o mundo e a preocupação crescente em relação à quantidade e qualidade deste bem vital deixou de ser apenas da comunidade científica, passando a interessar também a diversos segmentos da população.

No Brasil, especificamente na região de Ribeirão Preto (SP), a consciência da sociedade em relação à gestão racional e sustentável dos recursos hídricos subterrâneos já é realidade, principalmente porque a questão vem sendo exposta e debatida já há alguns anos. Tal preocupação decorre do fato do abastecimento integral de água do município ser proveniente do Aqüífero Guarani, um dos maiores e mais importantes reservatórios de água subterrânea do Cone Sul (ROCHA, 1996;EMBRAPA, 1999a). Neste contexto têm surgido vários questionamentos sobre a preservação da qualidade e manutenção da quantidade da água subterrânea na região, começando por análises críticas das prováveis fontes de poluição, com especial atenção para as áreas de recarga, situadas ao leste da cidade de Ribeirão Preto. O consumo passou também a ser analisado, uma vez que em períodos de estiagem (abril a setembro) têm sido observados rebaixamentos da ordem de 20 metros no nível piezométrico do reservatório subterrâneo que representa o Aqüífero Guarani na região.

A agricultura, dentre outras atividades, passou a ser considerada como uma fonte potencial de poluição da água subterrânea, principalmente porque as áreas de recarga do aqüífero, em discussão, têm sido ocupadas com cultivo intensivo de cana-de-açúcar. Diante deste cenário e atendendo demanda de diversos segmentos da comunidade, a EMBRAPA - Meio Ambiente propôs estudo para avaliação de impactos gerados pela atividade agrícola em áreas diagnosticadas como sendo de risco de contaminação de aqüíferos, considerando a presença de agrotóxicos e nitrato, tanto no solo quanto na água subterrânea. Para tanto, foi escolhida a microbacia do Córrego Espraiado, com área de 4.640 ha, cuja nascente encontra-se às margens da Via Anhanguera (SP-330), na divisa dos municípios de Ribeirão Preto e Cravinhos (EMBRAPA, 1999a).

O presente trabalho teve como objetivo discutir aspectos relativos à ocorrência do herbicida Tebuthiuron na água subterrânea da microbacia do Córrego Espraiado, no período compreendido entre os anos de 1995 e 1999, principalmente por oferecer risco potencial de contaminação da água subterrânea. 


\section{MATERIAL E MÉTODOS}

\subsection{CARACTERIZAÇÃO FISIOGRÁFICA DA ÁREA DE ESTUDO}

A área objeto de estudo situa-se entre as coordenadas $21^{\circ} 05^{\prime} \mathrm{e}$ $21^{\circ} 20^{\prime}$ de latitude sul e $47^{\circ} 40^{\prime}$ e $47^{\circ} 50^{\prime}$ de longitude W.Gr. A altitude média é de $600 \mathrm{~m}$ e o relevo dominante do tipo suave ondulado. O solo é constituído predominantemente por Latossolo Vermelho Eutroférrico e Distroférrico, classificados pelo Sistema Brasileiro mais antigo como Latossolo Roxo dos tipos eutrófico e distrófico em proporções semelhantes (MIKLÓS \& GOMES, 1996). Na porção mais jusante da área representativa da recarga do Aqüífero Guarani predominam solos arenosos do tipo Latossolo Vermelho Distrófico psamítico e Neossolo Quartzarênico (EMBRAPA, 1999b). O último constitui-se no solo típico das áreas de recarga, cujas características físicas são apresentadas no Quadro 1.

\section{QUADRO 1- CARACTERÍSTICAS FÍSICAS DO NEOSSOLO QUARTZARÊNICO(RQ) DA MICROBACIA DO CÓRREGO ESPRAIADO}

\begin{tabular}{|c|c|c|c|c|}
\hline $\begin{array}{l}\text { Profundidade } \\
\quad \text { (cm) }\end{array}$ & $\begin{array}{c}\text { Carbono org nico } \\
(\%)\end{array}$ & $\begin{array}{c}\text { Macroporosidade } \\
(\%)\end{array}$ & $\begin{array}{l}\text { Microporosidade } \\
(\%)\end{array}$ & $\begin{array}{c}\text { Condutividade } \\
\text { hidr/伍lica }(\mathrm{cm} / \mathrm{h})\end{array}$ \\
\hline$P-0-20$ & 0,30 & 29,60 & 15,03 & 16,79 \\
\hline P-20-40 & 0,24 & 32,04 & 30,49 & 10,69 \\
\hline P-40-60 & 0,20 & 29,89 & 31,14 & 16,31 \\
\hline P-60-80 & 0,13 & 29,67 & 12,61 & 13,80 \\
\hline P- $80-100$ & 0,08 & 32,45 & 25,11 & 16,00 \\
\hline P-100-120 & 0.03 & 35,42 & 26,24 & 18,83 \\
\hline
\end{tabular}

A vegetação original era composta por mata tropical a subtropical subcaducifólia. A geologia é constituída por dois litotipos distintos: rochas basálticas da Formação Serra Geral a montante e arenitos da Formação Botucatu a jusante da área. Sob o ponto de vista climatológico, a área está inserida na classificação climática do tipo tropical de inverno seco de savana (AW) conforme Köppen. A temperatura média anual oscila entre 21 e $22^{\circ} \mathrm{C}$. A precipitação anual varia de 1300 a $1500 \mathrm{~mm}$, sendo os dados de precipitação mensal referentes ao período de realização do trabalho apresentados nas Figuras 1 e 2 . A evapotranspiração potencial, obtida pelo método de Thorntwaite, atinge $1000 \mathrm{~mm} / \mathrm{ano}$. No caso da 
hidrogeologia regional destaca-se o Aqüífero Guarani, com área de recarga de $16.000 \mathrm{Km}^{2}$ no Estado de São Paulo (IAC, 1990; IGC, 1990; SÃO PAULO, 1997).

FIGURA 1 - DADOS MENSAIS DE PRECIPITAÇÃO NA MICROBACIA DO CÓRREGO ESPRAIADO REFERENTES AOS ANOS DE 1995, 1996 E 1997

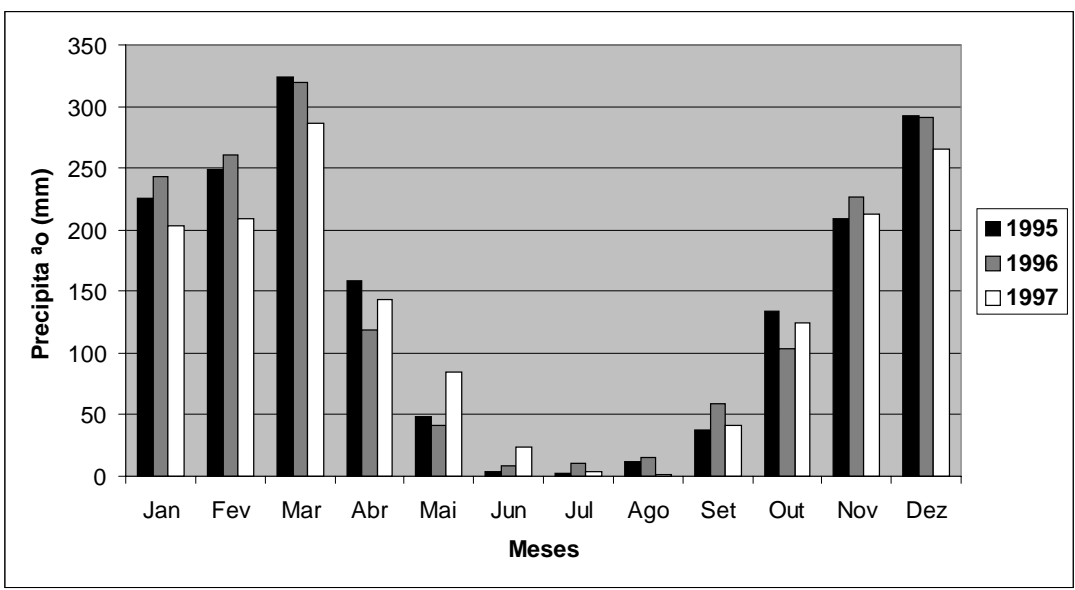

FIGURA 2 - DADOS MENSAIS DE PRECIPITAÇÃO NA MICROBACIA DO CÓRREGO ESPRAIADO REFERENTES AOS ANOS DE 1998 E 1999

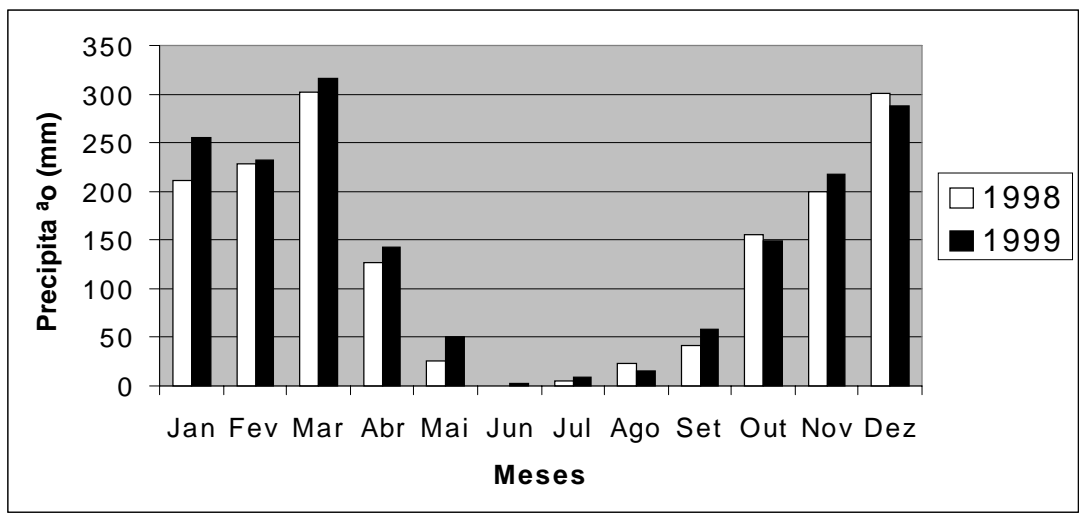


A seleção do agrotóxico, discutido neste trabalho, teve por base a intensidade de uso (quantidade e freqüência de aplicação), conforme o Quadro 2 e o potencial de lixiviação, classificado de acordo com o índice de GUS, proposto por GUSTAFSON (1989).

\section{QUADRO 2- PESTICIDAS/HERBICIDAS MAIS USADOS E RESPECTIVAS DOSES (kg i.a./ha e L i.a./ha) NA MICROBACIA DO CÓRREGO ESPRAIADO NO PERÍODO DE 1993 A 1998}

\begin{tabular}{|c|c|c|c|c|c|c}
\hline HERBICIDAS & \multicolumn{7}{|c}{ ANO DE APLICA ^ O } \\
\cline { 2 - 7 } & 1993 & 1994 & 1995 & 1996 & 1997 & 1998 \\
\hline Diuron & 2,5 & 1,2 & 1,2 & 1,2 & 1,2 & 1,2 \\
Ametrina & 2,0 & 1,5 & 1,5 & 1,5 & 1,5 & 1,5 \\
Tebuthiuron & 0,5 & 1,1 & 1,1 & 1,1 & 1,1 & 1,1 \\
Hexazinone & - & 0,3 & 0,3 & 0,3 & 0,3 & 0,3 \\
\hline
\end{tabular}

i.a. $=$ ingrediente ativo.

A dose reduzida de Tebuthiuron usada no ano de 1993 foi devido à mistura com Ametrina totalizando aplicação conjunta de $2,5 \mathrm{~kg}$ i.a./ha. A partir de 1994, a combinação foi ajustada passando o Tebuthiuron a ser aplicado conforme a dose normal recomendada (1,1 kg i.a/ha) e a Ametrina conforme a dose mínima recomendada (1,5 kg i.a./ha).

GUSTAFSON (1989) utilizou metodologia para examinar graficamente as propriedades de mobilidade e persistência no solo de agrotóxicos, no sentido de observar o agrupamento de compostos lixiviáveis. Segundo o referido autor esse método é adequado como a primeira parte de uma abordagem de aproximações sucessivas para especificar quais produtos deveriam receber mais atenção durante estudos mais demorados e caros de lixiviabilidade em pequena escala.

O índice de GUS (GUSTAFSON, 1989), por sua vez, é calculado pela seguinte equação:

$$
\mathrm{GUS}=\log \left(\mathrm{t}_{1 / 2}\right) \cdot(4-\log (\mathrm{Koc}))
$$


Determinado o índice GUS para os herbicidas utilizados, os mesmos podem ser classificados em três categorias distintas, ou seja, GUS $<1,8$ = não-lixiviável; GUS > 2,8 = lixiviável; e 1,8 < GUS $<2,8$ = faixa de transição. Dados de meia-vida (t $1 / 2)$ e coeficiente de sorção (Koc) foram coletados na literatura e são apresentados no Quadro 3, assim como o índice GUS calculado para cada herbicida. Como, dentre os pesticidas mais usados na microbacia, o Tebuthiuron apresentou o maior potencial de lixiviação, este foi selecionado para monitoramento de sua ocorrência em água subterrânea na área em estudo. O Tebuthiuron apresenta combinação relativamente baixa de sortividade (Koc) com longa meiavida $\left(t^{1} / 2\right)$ no solo, o que resulta em alta lixiviabilidade.

\section{QUADRO 3 - CLASSIFICAÇÃO DOS PESTICIDAS/HERBICIDAS MAIS USADOS NA MICROBACIA DO CÓRREGO ESPRAIADO, CONFORME O POTENCIAL DE LIXIVIAÇÃO EXPRESSO PELO ÍNDICE GUS (GUSTAFSON, 1989)}

\begin{tabular}{|c|c|c|c|}
\hline Pesticida/Herbicida & $\mathrm{Koc}(\mathrm{mL} / \mathrm{g})$ & t\%o (dias) & GUS \\
\hline Ametrina & 300 & 60 & 2,7 \\
\hline Diuron & 480 & 90 & 2,6 \\
\hline Hexazinone & 54 & 90 & 4,4 \\
\hline Tebuthiuron & 80 & 360 & 5,4 \\
\hline
\end{tabular}

Koc = coeficiente de sorção.

$\mathrm{t}^{1} / 2=$ meia-vida.

\subsection{AMOSTRAGEM}

Procedeu-se à amostragem da água do poço semi-artesiano da Fazenda São José, localizada na microbacia do Córrego Espraiado, cuja profundidade é de 53 metros, definido como poço de monitoramento. A sistemática de coleta de amostras de água obedeceu a captação direta em recipiente de vidro âmbar de $1000 \mathrm{~mL}$, a partir de torneira junto ao poço, em períodos mensais (outubro, novembro e dezembro) durante 0 ano de 1995, e bimestrais durante os anos de 1996, 1997, 1998 e 1999. As amostras de água para análise foram compostas de 4 alíquotas tomadas em diferentes profundidades no recipiente de $1000 \mathrm{~mL}$ (amostragem composta), conforme EMBRAPA, 1999a.

No caso da amostra-testemunha foi usado o poço semi-artesiano do núcleo residencial denominado Recreio Internacional, obedecendo-se 
os seguintes critérios: a) características semelhantes ao poço de monitoramento, tais como profundidade do nível piezométrico, altimetria da boca do poço e mesma formação geológica; b) maior proximidade possível do poço objeto de monitoramento; c) ausência do herbicida Tebuthiuron em três amostras tomadas no período de um mês (EMBRAPA, 1999a).

\subsection{ANÁLISE DA ÁGUA}

As amostras de água foram submetidas a análises cromatográficas. A solução-padrão de Tebuthiuron (99,8\%, Chemical Service) foi preparada em metanol grau cromatografia (Mercck). As soluções-estoque para Tebuthiuron foram preparadas nas concentrações de $1,0 \mathrm{mg} / \mathrm{mL}$ e diluídas para obtenção de soluções nas concentrações de 0,$08 ; 0,20 ; 0,32$ e $0,40 \mu \mathrm{g} / \mathrm{mL}$.

Foi empregado cromatógrafo a líquido marca Shimadzu, em sistema isocrático, constituído por duas bombas ( $L C-10 A D)$, dois detectores espectrométricos de absorbância no ultravioleta (SPD-10A e SPDAV) operando em $220 \mathrm{~nm}$ e $254 \mathrm{~nm}$, injetor automático (SIL 10A) com amostrador de $100 \mu \mathrm{L}$ e dois integradores C-R6A Chromatopac. A separação foi obtida em coluna de fase reversa Lichrospher ${ }^{\circledR} 100$ RP-8 partículas de $5 \mu \mathrm{m}, 125 \times 4 \mathrm{~mm}$ (Merck), com pré-coluna Lichospher ${ }^{\circledR} 100$ RP-8 partículas de $5 \mu \mathrm{m}$ (Merck), usando como fase móvel tampão fosfato $0,05 \mathrm{M}, \mathrm{pH}$ 5,5 e acetonitrila na proporção 73:27 v/v, em fluxo de $1 \mathrm{~mL} / \mathrm{min}$. O limite de detecção do equipamento foi de $0,02 \mu \mathrm{g} / \mathrm{L}$ (SANTOS et al., 1997).

Para efeito de referência da qualidade da água foi adotado o padrão de potabilidade recomendado pela Organização Mundial de Saúde para a Europa, principalmente, por considerar valores mais restritivos do que aqueles estabelecidos pela Portaria no 1469 do Ministério da Saúde (2000). Enquanto aquela adota valores de $0,1 \mu \mathrm{g} / \mathrm{L}$ por pesticida e $0,5 \mu \mathrm{g} / \mathrm{L}$ por pesticidas totais (CETESB, 1997), a Portaria mencionada considera valores muito mais elevados, levando em conta ainda número relativamente pequeno de agrotóxicos, frente ao número real usado no país.

\section{RESULTADOS E DISCUSSÃO}

Os resultados obtidos em relação à presença do herbicida Tebuthiuron (Figura 3) correspondem às amostragens efetuadas durante os meses de outubro, novembro e dezembro de 1995, e durante os meses de janeiro, março, maio, julho, setembro e novembro dos anos de $1996 \mathrm{e}$ 
1997. Os dados obtidos para os meses de janeiro, março, maio, julho, setembro e novembro dos anos de 1998 e 1999 constam da Figura 4.

\section{FIGURA 3 - RESÍDUOS DE TEBUTHIURON NA ÁGUA SUBTERRÂNEA EM POÇO LOCALIZADO NA MICROBACIA DO CÓRREGO ESPRAIADO-1995/1996/1997}

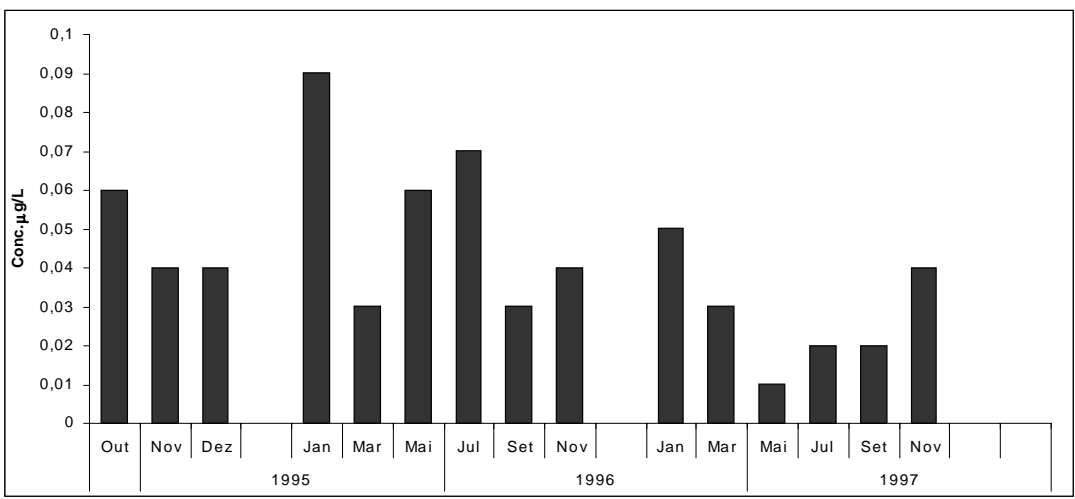

O método de seleção de pesticidas, considerando a intensidade de uso juntamente com a utilização do índice GUS, mostrou-se válido, pois o herbicida selecionado foi encontrado na água subterrânea.

No ano de 1995, valor comparativamente elevado de Tebuthiuron foi encontrado no mês de outubro decrescendo nos meses subseqüentes para voltar a aumentar no mês de janeiro de 1996. Embora não se tenha informações precisas sobre o efeito residual e cumulativo do Tebuthiuron na água subterrânea, em função de aplicações sucessivas, nota-se tendência de concentração do mesmo no mês de janeiro para todos os anos estudados.

Considerando os aspectos acima como válidos e, uma vez corroborados pelos valores de concentração relativamente elevados, principalmente nos meses de janeiro, pode-se dizer que o Tebuthiuron oferece risco de contaminação para a água subterrânea. No mês de janeiro de 1996, por exemplo, a concentração aproximou-se do nível crítico para o padrão de potabilidade que é de $0,10 \mu \mathrm{g} / \mathrm{L}$, atingindo o valor de $0,09 \mathrm{ug} / \mathrm{L}$. No ano de 1997 a concentração maior continuou ocorrendo no mês de janeiro, embora inferior ao mesmo mês no ano de 1996 (Figura 3).

Ao analisar os dados de concentração do Tebuthiuron, referentes aos anos de 1998 e 1999 (Figura 4), percebe-se a mesma tendência de comportamento em relação aos anos de 1996 e 1997, com destaque 
para janeiro de 1999, quando houve grande proximidade do valor considerado crítico para o padrão de potabilidade. Da mesma forma como foi comentado para aqueles dois anos supõe-se que no mês de janeiro de 1999 houve processo de realimentação do aqüífero ocasionado pelo alto índice de precipitação no período. Tal fato teve como conseqüência o arraste das moléculas de Tebuthiuron em concentração expressiva, ao ponto de neutralizar o efeito diluidor da água que atuou como agente condutor da referida molécula até a zona saturada do aqüífero.

\section{FIGURA 4 - RESÍDUOS DE TEBUTHIURON NA ÁGUA SUBTERRÂNEA COLETADA EM POÇO LOCALIZADO NA MICROBACIA DO CÓRREGO ESPRAIADO-1998/1999}

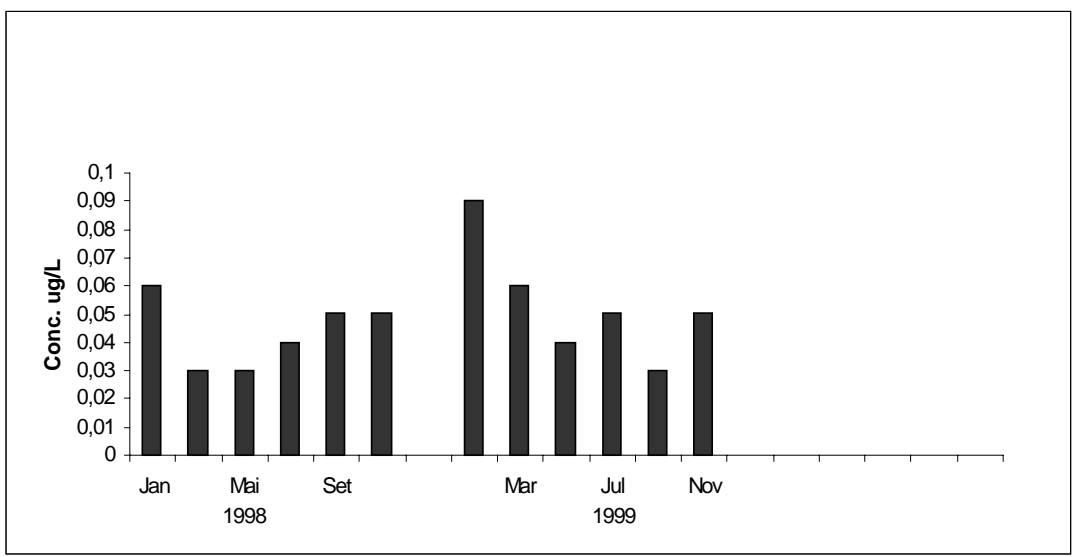

O Tebuthiuron pode ser aplicado em qualquer época do ano, tanto no período chuvoso como no seco, concentrando-se, porém, nos meses de outubro, novembro e dezembro na microbacia estudada. Os resultados com maiores valores de concentração residual de Tebuthiuron na água subterrânea nos meses chuvosos podem ser indicativos de que: (a) a lixiviação é muito intensa e imediata ou (b) a degradação diminui drasticamente em profundidade no solo. O primeiro ponto pode ser baseado na grande condutividade hidráulica do solo estudado (Quadro 1). Além disso, a profundidade do topo do aqüífero varia sazonalmente de acordo com a quantidade de chuva, alterando a condutividade hidráulica nas camadas profundas do solo, sendo maior em condições saturadas que em condições insaturadas. O outro ponto levantado pode ter respaldo no fato de que o Tebuthiuron sofre degradação microbiana e química. $O$ 
Tebuthiuron é persistente em solos, sendo esperado que sua meia-vida seja ainda mais longa em regiões e/ou épocas secas (WSSA, 1994). Também é conhecido que a capacidade de retenção (sorção) do herbicida é baixa já nas camadas superficiais do solo na área estudada devido ao baixo teor de matéria orgânica apresentado (Quadro 1).

Estudos de simulação do movimento vertical do Tebuthiuron têm sido efetuados em solos arenosos das áreas de recarga do Aqüífero Guarani, indicando que o produto oferece riscos para a água subterrânea (PESSOA et al., 1998 e PESSOA et al., 1999). De qualquer forma, há necessidade de se desenvolver estudos de comportamento do herbicida Tebuthiuron, por períodos mais prolongados, para confirmar a veracidade das considerações expressas anteriormente.

\section{CONCLUSÃO}

O monitoramento do herbicida Tebuthiuron, por si só, não subsidia o entendimento dos processos de seu movimento até a água subterrânea, mas comprova que o fenômeno realmente está acontecendo e de forma muito rápida em solos arenosos, necessitando de investigações mais detalhadas.

As características físicas dos solos da área estudada ressaltam a sua expressiva vulnerabilidade natural que, aliada ao alto potencial de lixiviação e outras propriedades físico-químicas do herbicida Tebuthiuron, refletem situação de risco potencial de contaminação da água subterrânea, principalmente em relação ao padrão de potabilidade.

O método de seleção de pesticidas proposto foi capaz de identificar pesticidas/herbicidas potencialmente lixiviáveis para águas subterrâneas.

Estudos de simulação do movimento do Tebuthiuron com a conseqüente validação em campo permitirão a avaliação de riscos mais efetivos ou reais de contaminação da água subterrânea.

\section{Abstract \\ OCCURRENCE OF THE HERBICIDE TEBUTHIURON IN GROUNDWATER OF ESPRAIADO CATCHMENT RIBEIRAO PRETO - SP (BRASIL)}

The herbicide Tebuthiuron, selected among others utilized in sugar-cane crop, shows groundwater contamination risk due to its physicochemical properties, mainly, when applied in direct recharge areas of aquifers considered of high natural vulnerability. In this context, the monitoring of this herbicide in the period of 1995 through 1999 was realized, by collecting water samples of aquifers $53 \mathrm{~m}$ depht, located in Espraiado 
catchment, Ribeirao Preto/SP (Brazil) in which the product has been extensively used. For blank assays it was utilized water samples collected similarly $3 \mathrm{Km}$ away from the monitoring area. The results obtained showed that Tebuthiuron is present in all analyzed samples. Although in lower concentrations of the critical level for drinkable water, following the restrictive limits established by World Health Organization (for pesticides in use is $0,1 \mu \mathrm{g} / \mathrm{L}$ by pesticide and of $0,5 \mu \mathrm{g} / \mathrm{L}$ for total pesticides). Even if the low concentration values found it is evident that the Tebuthiuron affects the groundwater, and could enhance its concentration by favorable ambiental conditions for molecule preservation in deep water (such as low temperature, low biological activity and absence of light). The present scenary reflects contamination risk in case of reaching the critical level, which could only be minimized by the substitution of Thebuthiuron for other herbicide with lower soil mobility.

KEY-WORDS: TEBUTHIURON; GROUNDWATER; AQUIFER.

\section{REFERÊNCIAS}

1 BRASIL. Ministério da Saúde. Portaria n. 1469 de 29 dez. 2000. Aprova as normas de qualidade de água para consumo humano. Diário Oficial [da] República Federativa do Brasil, Brasília, 2 de jan. de 2001. p. 19.

2 CETESB. Companhia de Tecnologia de Saneamento Ambiental. Relatório de qualidade das águas subterrâneas do Estado de São Paulo. São Paulo, 1997. 106 p.

3 EMBRAPA. Impacto ambiental e implicações sócio-econômicas da agricultura intensiva em água subterrânea. Jaguariúna, 1999a. 36 p. (Relatório final de projeto).

4 EMBRAPA. Sistema brasileiro de classificação de solos. Rio de Janeiro: Embrapa Solos, 1999b. 412 p.

5 GUSTAFSON, D.I. Groundwater ubiquity score: a simple method for assessing pesticide leachability. Environmental Toxicology and Chemistry, v.8, n. 4, p. 339-357, 1989.

6 IAC. Instituto Agronômico de Campinas. Carta pedológica semidetalhada do Estado de São Paulo: quadrícula Ribeirão PretoSP. São Paulo: IGC, 1990. Escala 1:100.000.

7 IGC. Instituto Geográfico e Cartográfico. Plano cartográfico do Estado de São Paulo: folhas SF-23-V-C-I-2-SO-D, SF-23-V-C-I-2- 
SO-E, SF-23-V-C-I-2-SO-F, SF-23-V-C-IV-3-SE-D, SF-23-V-C-I-IV-3SE-F e 23-V-C-I-3-NE-B. São Paulo: IGC, 1990. Escala 1:10.000.

8 MIKLÓS, A.A.W.; GOMES, M.A.F. Levantamento semidetalhado dos solos da bacia hidrográfica do Córrego do Espraiado, Ribeirão Preto-SP. Jaguariúna: EMBRAPA-CNPMA, 1996. 48 p. (Relatório de Consultoria).

9 PESSOA, M.C.P.Y.; GOMES, M.A.F.; DORNELAS DE SOUSA, M.; NICOLELLA,G.; CERDEIRA, A.L., MONTICELLI, A. Simulação de herbicidas utilizados no monocultivo de cana-de-açúcar em latossolos da área de recarga do Aqüífero Botucatu (Guarani) em Ribeirão Preto, SP. R. Cient. Rural, v. 4, n.1, p. 15-24, 1999.

10 PESSOA, M.C.P.Y.; GOMES, M.A.F.; DORNELAS DE SOUSA, M.; NICOLEL-LA,G.; CERDEIRA, A .L.; MONTICELLI, A. Simulação do movimento de herbicidas utilizados no monocultivo de cana-de-açúcar em areia quartzosa da área de recarga do Aqüífero Guarani (antigo Botucatu) em Ribeirão Preto, SP. R. Cient. Rural, v. 3, n. 2, p. 1119, 1998.

11 ROCHA, G.A. Mega reservatório de água subterrânea do Cone Sul: bases para uma política de desenvolvimento e gestão. Curitiba, UFPR/IDRC 1996. $25 \mathrm{p}$.

12 SANTOS, N.A.G.; BONATO, P.S.; DREOSSI, S.A.C.; GOMES, M.A.F.; CERDEIRA, A.L.; CARVALHO, D.; LANCHOTE, V.L. Multiresidue method for the analysis of herbicides in surface and groundwater. B. Chim. Farmaceutico, v. 2, n. 136, p. 133. 1997.

13 SÃO PAULO. Instituto Geológico. Mapeamento da vulnerabilidade e risco de poluição das águas subterrâneas no Estado de São Paulo. São Paulo: IG/CETESB/DAEE, 1997. 144 p.

14 WSSA. Weed Science Society of America. Herbicide handbook. $7^{\text {th }}$ ed. Champaign, IL, 1994. p. 9-5. 